\title{
OPTIMISATION OF CONSTRUCTION PROCESS INSPECTION RATES USING A LEARNING APPROACH
}

Swapan Saha, Colin J Greville and Trevor A Mullins, the University of Western Sydney, New South Wales, Australia

\section{Introduction}

In a construction process, inspection/tests are an important activity. Without inspection a task cannot be completed successfully. Inspections/tests are normally carried out before and after the execution of a task. To prevent occurrence of errors in a construction process inspections are considered as an essential activity.

The Construction Industry Development Agency in Australia (CIDA, 1995) has estimated the direct cost of rework in construction to be grater than $10 \%$ of project cost. Blyth (1995) comments in a compilation of existing case studies, that construction company, Sinclair Knights Merz's, rough estimate of quality system cost is $2 \%$ of turnover. Blyth's (1995) study also suggested that actual cost incurred on the quality system is difficult to determine. Davis et al. (1989) reported that the cost of providing quality assurance and quality control in engineered construction was estimated to be approximately up to $5 \%$. Therefore total cost of quality, including rework, can be up to $15 \%$ of the total project cost. According to Love and $\mathrm{Li}$ (2000), cost incurred on appraisal in construction (eg. inspection and testing cost) is approximately $30 \%$ of the total quality cost or approximately up to $4.5 \%$ ( $30 \%$ of $15 \%$ of total project cost) of the total project cost. The total value of the annual turnover of the Australian construction industry was estimated, in 1996 , to be $\$ 43.5$ billion (DIST 1998). Thus, if a $4.5 \%$ of the appraisal (inspection \& testing) value applied to this total annual turnover, then the approximate cost of inspection and testing could be estimated to be $\$ 2.0$ billion per annum.

According to above findings a significant proportion of the project cost savings can be achieved with the optimisation of inspection policy. To achieve a $100 \%$ quality level for a constructed facility, effort and time spent on inspection may not be cost effective. Therefore, optimisation of inspection costs based on certain quality levels would be valuable. The $100 \%$ inspection is the common practice in the construction industry. With the modernisation and repetition of the construction activity a lower inspection rate (the less than $100 \%$ inspection) in a construction is more realistic and cost effective.

There are a number of sampling methods which are utilised to optimise the inspection cost in the manufacturing industries. Methods that are available include the single sampling plan, double sampling plan, multiple sampling plan, acceptance sampling, operating characteristic curve, and attribute proportional sampling (APS) (Grant and Leavenworth 1988, Hines and Montogomery 1990 and Chan and Hsie 1995, Dhillon 1985 and Leitch, 1988). In this paper suitable sampling plans for the construction industry are briefly discussed.

For a stable process, acceptance-sampling plan is invalid because the number of defectives in a sample is not correlated with the number of defective items in the remainder of the lot. A proof of this theory is given by Gitlow et al. (1987). For a cost effective inspection policy acceptance sampling does not include the calculation of optimum sample size. Minimum cost Method is discussed in this study to overcome this limitation.

The minimum cost model ( $\mathrm{MCM}$ ) is developed using different categories of quality costs, namely prevention cost, appraisal cost and failure/rectification cost. A systematic breakdown of these costs is given in this study. An example is presented to clarify how the number of tests, or inspections to be performed per construction task is dependent on the cost 
of inspection/test and the probability of occurrence of defects.

\section{Determination of Sample Size}

This section discusses the number of samples that need to be inspected to establish the level of confidence that the owner is seeing. In order to limit sampling

$s=\sqrt{\frac{p(1-p)}{n}}$

where, $\mathrm{n}$ is sample size

This will help set the minimum value of $n$ required and, if the desired defective values are not obtained, indicate the maximum value of $n$ required. The limits of accuracy on the number tests can be calculated using the equation (2):

$\mathrm{U}_{\mathrm{L}}=\mathrm{p} \pm \mathrm{Z}() \mathrm{s}$

Where, $U_{L}$ is the limits of acceptable proportion defective.

The calculation of sample size depends on a number of factors including criteria of errors the average proportion of defective constructed products which the owner is willing to accept will have to be specified. This will be in the form of $p \pm Z()$ s where $p$ is the average proportion defective (error rate), $Z()$ is the value found in normal distribution table for a specified confidence interval and $\mathrm{s}$ is the standard deviation for a binomial distribution expressed as follows: acceptance and rejection and cost of inspection and rejection.

\section{Criteria of Acceptance and Rejection}

In the construction industry inspection/testing of every item is often done. This however is not always possible, particularly when inspection/testing is expensive and time consuming.

In the case of batch construction, the inspection/testing of a few items that are selected randomly can minimise the overall construction cost including the project duration. In this case there is a degree of risk attached to both the contractor and the owner. The accept/reject criteria for the batch under inspection/testing can be based on the following hypothesis.

\begin{tabular}{|lll|}
\hline If & $p \leq Q$ & accept \\
If & $p>Q$ & reject \\
\hline
\end{tabular}

Where, $p$ is the estimated average proportion defective and $Q$ is the allowable maximum proportion defective for the lot, $p$ and $Q$ can be defined as below:

$$
\begin{aligned}
& p=r / n \\
& Q=c / n
\end{aligned}
$$

where $r$ the number of non-conforming items in a sample and $\mathrm{c}$ is the maximum allowable non-conforming items in the sample. The sample size, $\mathrm{n}$ and acceptable number of defective items has to be agreed by the owner and the contractor. There are a number of sampling plans available to determine the sample size including single sampling plan, double sampling plan, multiple sampling plan, \& attribute proportional sampling plan. The sampling plans are pictorially represented by the operating characteristics curve (OC curve). The characteristics of an OC curve are outlined below.

\section{Operating Characteristics Curve}

In an OC curve the probability of accepting the batch, $\mathrm{Pa}$ is plotted against the proportion of defective items $(p)$. The distribution for $p$ can be selected based on the sample size. The popular probability distributions available for the calculation of $p$ include the hyper-geometric, the Binomial and the Poisson's distributions. Further details about the OC curve can be found in Hines and Montogomery (1990) and Grant and Leavenworth (1988). 
There are several parameters for a typical OC Curve as represented in Figure 1.

These parameters are defined as below:

- the contractor's risk $(\alpha)$ : $\alpha$ is the risk of rejection of a lot where the proportion of defective is $p 1$,

- the owner's risk $(\beta): \beta$ is the risk of acceptance of a lot where the proportion of defective is $\mathrm{p} 2$,
- the lot tolerance proportion defective (LTPD): proportion defective in a lot of items is at unacceptable quality level, at which the acceptance probability is very low. It is associated with the Principal's risk, and,

- the acceptance quality level (AQL): the maximum proportion of defective items.

Figure 1 Typical OC curve

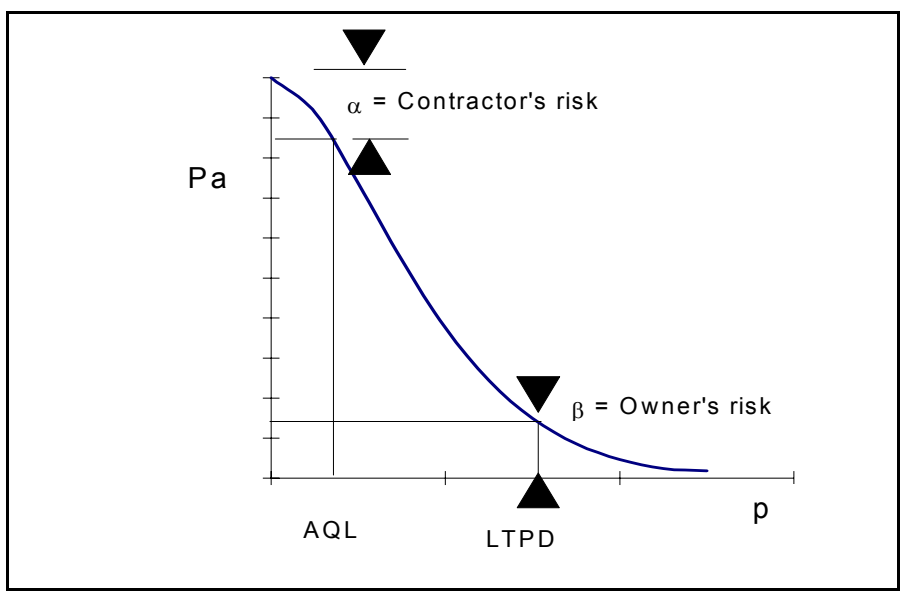

If $\mathrm{p}_{1}, \mathrm{p}_{2}, \alpha$ and $\beta$ are known then $\mathrm{n}$ and $\mathrm{c}$ can be calculated using Poisson's and binomial distributions.

From the OC curve it is clear that a high probability of acceptance means high quality. Selection of the values of $n$ and $c$ are important here. Values of $n$ and $c$ must be chosen in a way which will satisfy both principal and contractor.

The contractor's risk is the chance that a high number of good quality products will be rejected. The principal 's risk is the chance that a high number of poor quality products will be accepted. The OC curve is plotted based on particular values of $n$ and c. A higher $c$ value gives rise to a higher risk for the principal. On the other hand higher $\mathrm{n}$ value introduces higher cost for the contractor. In order to satisfy both the principal and the contractor it is necessary to set optimum values for $\mathrm{n}$ and $\mathrm{c}$, which will result in minimum risk for both the principal and the contractor. The following section will describe the suitable sampling plans which can be used in the construction industry specifically the double sampling plan and the attribute proportional sampling plan.

\section{Double Sampling Plan}

The double sampling plan is considered to be more appropriate and cost-effective for the construction process in comparison to the single sampling plan. An example is presented below clarifying the double sampling plan. The example also discusses the concept of average outgoing quality (Grant and Leavenworth, 1988) and demonstrates that the double sampling plan is more cost effective and reliable than the single sampling plan.

Figure 2 outlines the details of the double sampling plan. In the double sampling plan a random sample size of $n_{1}$ is taken from the lot size, $\mathrm{N}$, and the number of defectives is say $r_{1}$. If $r_{1} \leq c_{1}$ the lot is accepted without further sampling. If 
$\mathrm{c}_{1}<\mathrm{r}_{1}<\mathrm{c}_{2}$ a second sample size of $\mathrm{n}_{2}$ is taken and the number of defectives, is say r2. Now, if $\left(r_{1}+r_{2}\right) \leq c_{2}$, then the lot is accepted, otherwise the lot is rejected

Figure 2 Schematic diagram for double sampling plan (adapted after Dhillon, 1985)

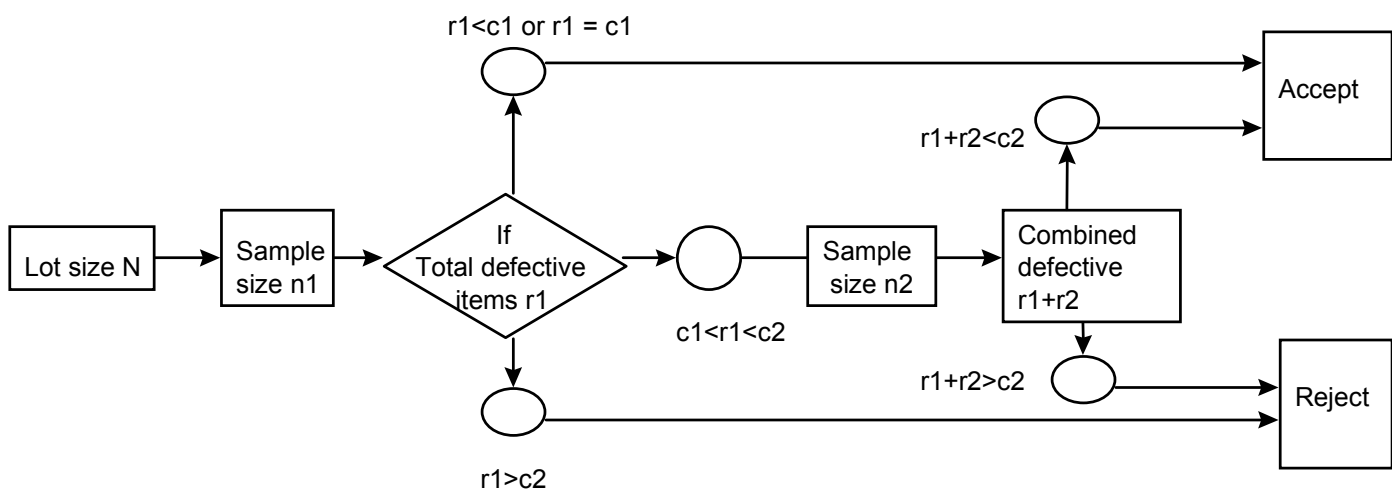

\section{Example}

In this example a double sampling plan involving large lots, uses $\mathrm{n}_{1}=5$ and $\mathrm{r}_{1}=0$, $\mathrm{n}_{2}=5$ and $\mathrm{c}_{2}=1$. Calculations for probability of acceptance $\left(\mathrm{Pa}_{\mathrm{a}}\right)$ using the Binomial distribution and Average Outgoing Quality (AOQ) for three sampling plans are given in the Table 1

Table 1

\begin{tabular}{|c|c|c|c|c|c|c|}
\hline $\mathbf{P}$ & $\begin{array}{l}P a \\
n=5, c=0\end{array}$ & $\begin{array}{l}P a \\
n=5, c=1\end{array}$ & $\begin{array}{l}P a \\
n=10, c=1\end{array}$ & $\begin{array}{l}\mathrm{AOQ} \\
\mathrm{n}=5, \mathrm{c}=0\end{array}$ & $\begin{array}{l}\mathrm{AOQ} \\
\mathrm{n}=5, \mathrm{c}=1\end{array}$ & $\begin{array}{l}A O Q \\
n=10, c=1\end{array}$ \\
\hline 0 & 1 & 1 & 1 & 0 & 0 & 0 \\
\hline 0.05 & 0.773784 & 0.9774 & 0.9138 & 0.03868905 & 0.04887 & 0.04569 \\
\hline 0.1 & 0.59049 & 0.9185 & 0.7361 & 0.059049 & 0.09185 & 0.07361 \\
\hline 0.15 & 0.443701 & 0.8352 & 0.5443 & 0.0665558 & 0.12528 & 0.081645 \\
\hline 0.2 & 0.32768 & 0.7373 & 0.3758 & 0.065536 & 0.14746 & 0.07516 \\
\hline 0.25 & 0.237309 & 0.6328 & 0.244 & 0.059327 & 0.1582 & 0.061 \\
\hline 0.3 & 0.16807 & 0.5283 & 0.1493 & 0.050421 & 0.15849 & 0.04479 \\
\hline 0.35 & 0.116026 & 0.4284 & 0.086 & 0.0406107 & 0.14994 & 0.0301 \\
\hline 0.4 & 0.07776 & 0.337 & 0.0463 & 0.031104 & 0.1348 & 0.01852 \\
\hline 0.45 & 0.050324 & 0.2562 & 0.0232 & 0.0226478 & 0.11529 & 0.01044 \\
\hline 0.5 & 0.03125 & 0.1874 & 0.018 & 0.015625 & 0.0937 & 0.009 \\
\hline
\end{tabular}

As mentioned previously there are two stages in the double sampling plan. These stages are:

Stage 1: $\quad$ take first sample $\mathrm{n}_{1}=5$

- $\quad$ if 0 defective items are found accept the lot

- if more than 1 defective items are found reject the lot
- $\quad$ if more than 0 and less 1 defective units are found the lot is of doubtful quality, then go to stage 2 for a decision

Stage 2: $\quad$ take additional sample $\mathrm{n}_{2}=5$

- if the total number of defectives found in both samples is less than or equal to 1 accept the lot 
- if the total number of defectives found in both samples is greater than 1 reject the lot.

In the case of single sampling plans involving $n=5, c=0$ and $n=10, c=1$, Figure 3 shows that the difference in average outgoing quality is negligible, but has twice the sample size compared to the double sampling plan. When using the double sampling plan for a particular lot, if the lot is accepted in the first stage then sampling size is automatically reduced by $50 \%$. Thus by choosing the double sampling method, the total cost of inspection or test can be reduced without affecting the reliability of the product.

\section{Figure 3 Operating characteristics curves and average outgoing quality for different sampling plans}

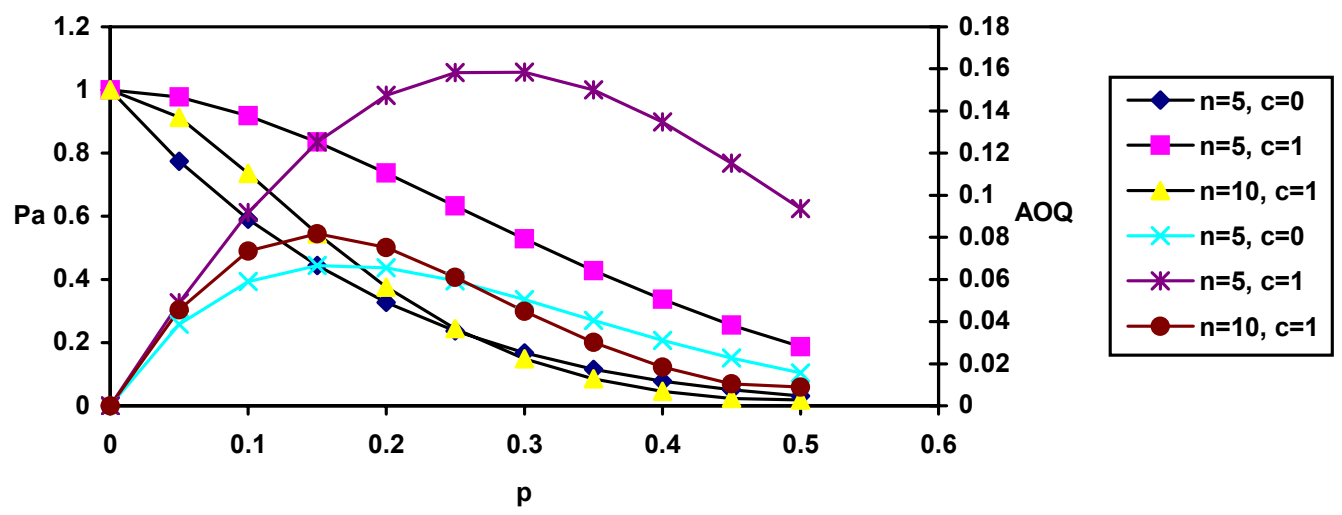

\section{Attribute-Proportional Sampling (APS) Method}

The attribute-proportional method is a simplified method to calculate the acceptable sample size when percentage defective, $p$ is known. APS is a modification of the error-margin method (Chang and Hsie, 1995). For a sample size $\mathrm{n}$, the binomial distribution of $\mathrm{p}$ of the sample is given in Figure 4:

$$
\begin{aligned}
& \mu(p)=p \\
& s=\sqrt{ }[p(1-p) / n]
\end{aligned}
$$

Figure 4 Standard deviation of $p$ for a binomial distribution

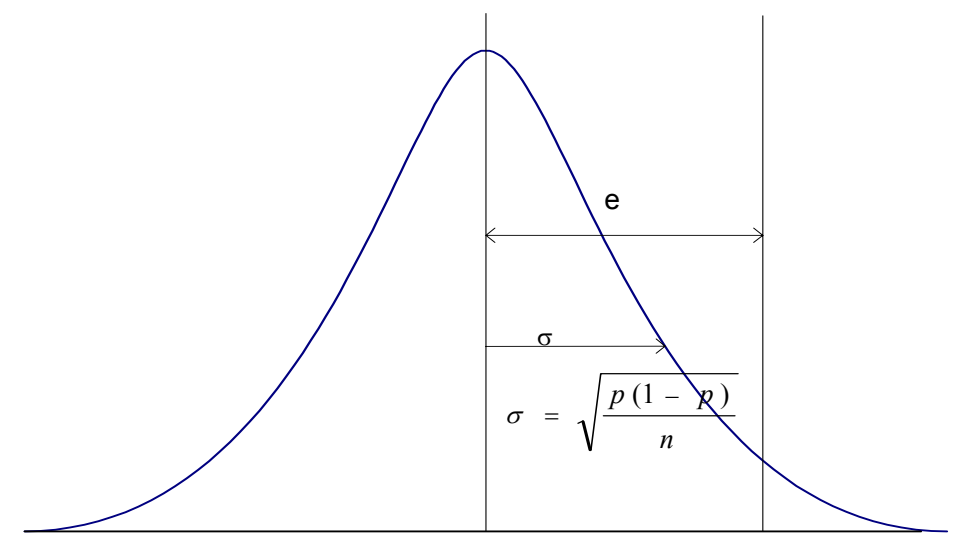


If the error margin e is known then the upper and lower limits of $p$ can be calculated for the confidence level (1- $\alpha)$. Therefore, the proportion defective (error rate) for a randomly selected sample should be within $\mathrm{p} \pm \mathrm{e}$ with the probability of . According to the binomial distribution error margin, e becomes:

$e=Z(1-\alpha / 2) \sigma_{p}=Z(1-\alpha / 2) \sqrt{\frac{p(1-p)}{n}}$

(5)

From equation (5) $\mathrm{n}$ can be derived as follows:

$\mathrm{n}=\frac{\mathrm{Z}^{2}(1-\alpha / 2)[\mathrm{p}(1-\mathrm{p})]}{\mathrm{e}^{2}}$

(6)

\section{Figure 5 Distribution of $p$ with respect to AQL and LTPD}

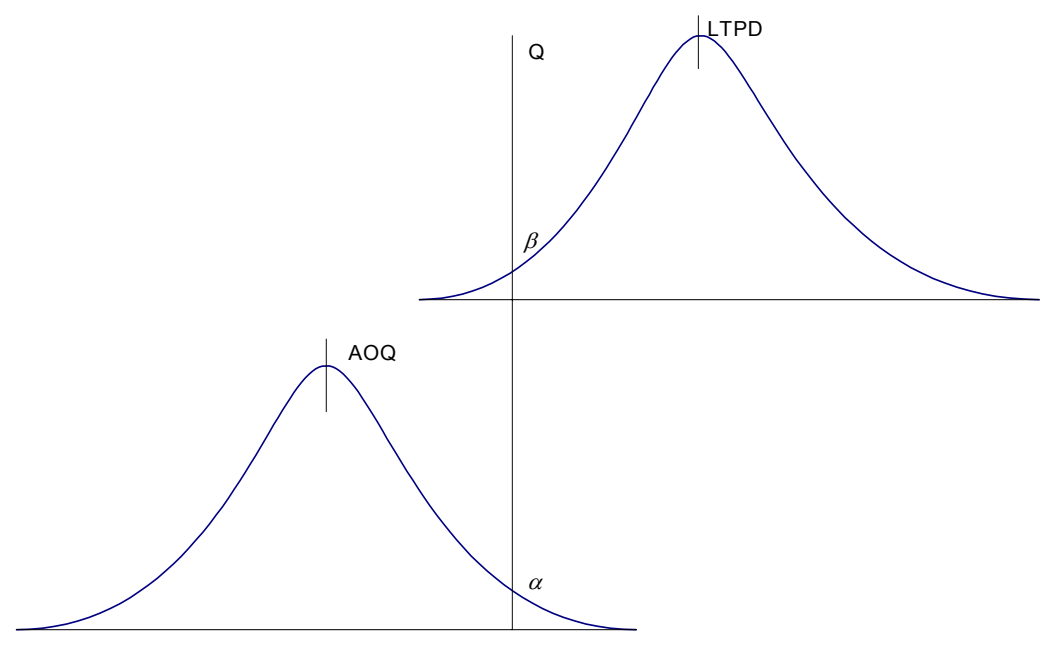

For a performance based contract it is necessary to incorporate owner's risk $(\beta)$ and contractor's risk $(\alpha)$. The APS method includes and and needs no assumption of $p$.

To derive the attribute-proportional sampling method two control points are utilised to determine the sample size and decision parameter $Q$. Here, $Q$ is the limit of percentage defective used to check
From equation (6) it is clear that the smaller the error margin (e), the higher the sample size. For a quality control system, the error margin (e), an acceptable proportion defective, $p$ and the confidence level, are specified by the owner. After knowing all the above parameters the sample size $n$ can be calculated. If the resultant proportion defective, $p(p=r / n)$ is smaller than the specified limits the lot will be accepted, otherwise it will be rejected.

However, the error margin method has two limitations (Chang and Hsie, 1995): i) assumption of $p$ in calculating $n$ is not correct; ii) the proportion defective (error rate) is unknown before inspection or testing. 
$\mu(p)=r / n$

$s=\sqrt{ }[p(1-p) / n]$

If $p$ is less than or equal to $Q$, then accept; and if $p>Q$ then reject. The probability of accepting LTPD quality is

$$
\begin{gathered}
\mathrm{Z}(\beta)=\frac{(\mathrm{Q}-\mathrm{LTPD})}{\sqrt{\frac{(\mathrm{LTPD}(1-\mathrm{LTPD})}{\mathrm{n}}}} \quad \begin{array}{l}
\text { table available in any } \\
\text { By solving equations } \\
\text { of } \mathrm{n} \text { and } \mathrm{Q} \text { can be deriv } \\
(11) \text { and }(12):
\end{array} \\
\mathrm{n}=\left[\frac{\mathrm{Z}(\alpha) \sqrt{\mathrm{AQL}(1-\mathrm{AQL})}+\mathrm{Z}(\beta) \sqrt{\mathrm{LTPD}(1-\mathrm{LTPD})}}{(\mathrm{AQL}-\mathrm{LTPD})}\right]^{2} \\
\mathrm{Q}=\mathrm{AQL}+\mathrm{Z}(\alpha) \sqrt{\frac{\mathrm{AQL}(1-\mathrm{AQL})}{\mathrm{n}}} \\
\text { or } \\
\mathrm{Q}=\mathrm{LTPD}-\mathrm{Z}(\beta) \sqrt{\frac{\mathrm{LTPD}(1-\mathrm{LTPD})}{\mathrm{n}}}
\end{gathered}
$$

The probability of rejecting AQL quality is given in equation (10)

$$
Z(\alpha)=\frac{(Q-A Q L)}{\sqrt{\frac{(A Q L(1-A Q L)}{n}}}
$$

$Z()$ can be found from a normal distribution table available in any statistics text book. By solving equations (9) and (10) the value of $n$ and $Q$ can be derived using equation where, $Q$ is the limits of average proportion defective, which is governed by the minimum value obtained from equation (12)

\section{Example}

Assume the owner would like to set the following conditions for a construction task: $\mathrm{AQL}=10 \%, \mathrm{LTPD}=30 \%$; control of the contractor's risk $(\alpha),=5 \%$; and the owner's risk $(\beta)=5 \%$. In this task the owner has specified lot size, $\mathrm{N}$ is quite large compare to $\mathrm{n}$, where $\mathrm{n}$, the sample size is 30 . Applying Equation (12) the upper limit of percentage defective $(\mathrm{Q})$ is found to be $19.04 \%$.

As we know the percentage defective $(p)$ is calculated by $r / n,(r=$ non-conforming items); if $p$ is smaller or equal to $Q$ then accept and if $p>Q$ then reject. Say, $r=5$ for the above task, therefore, percentage defective is $(5 / 30)^{*} 100=16.67 \%$ which is lower than $\mathrm{Q}=19.04 \%$ and is acceptable.

\section{Limitations of Acceptance Sampling Plan}

Acceptance sampling plans do not minimise the following: i) the total cost of inspection/testing of incoming and intermediary constructed items or services plus the cost to repair (rework) and inspect/test of these items or services in process or

ii) the total cost of inspection/testing of final constructed products or services that fail to meet the specifications because of defective goods or services used in production.

Acceptance sampling plans place an emphasis on inspection/testing, not on process improvement, in order to remove the need for inspection/testing when the process is stable.

If the process involves the inspection/testing of a stream of lots, ie. the population sampled is infinite, then the binomial distribution can be used to determine $p$. In the case of an isolated lot or if quality is important, then the use of the hyper-geometric distribution is appropriate. 
For a stable process, acceptance sampling is invalid because the number of defectives in a sample is not correlated with the number of defective items in the remainder of the lot. A proof of this theory is given by Gitlow et al. (1987).

For a cost effective inspection policy acceptance sampling does not include the calculation of optimum sample size.

Minimum cost method is discussed in this paper to overcome this limitation. Using this method by knowing a defective proportion and ratio of cost of inspection to cost of failure, optimum sample size can be calculated

\section{Optimal Inspection Policy}

Another consideration in determining the number of tests/inspections is the cost of inspection and the cost of replacement of defective products in the future. It is obvious that, the larger the number of inspection, the greater the confidence in the quality of the product. However, if the inspection cost is high compared with the replacement cost, then the number of inspections needs to be minimised. The number of inspections should be limited to the extent that gives the owner enough confidence that the product is of a desired/specified quality. The term 'enough confidence' can be expressed in statistical terms as the confidence interval. The Owner will have to be satisfied with a lesser number of inspections as the ratio of $\mathrm{C}_{t} / \mathrm{C}_{f}$ increases, where $\mathrm{C}_{t}$ and $\mathrm{C}_{\mathrm{f}}$ are the cost of prevention/appraisal and the cost of failure, respectively. A model is developed below to determine the optimal inspection policy. This model establishes a relationship between cost parameters, the sample size $(n)$, the lot size $(N)$ and the percentage defective $(p)$.

\section{The Minimum Cost Method (MCM) Model}

There is a minimum total cost for a certain quality level. This is illustrated in the classic quality cost trade-off model (Ittner, 1992) and is shown in Figure 6.

Total cost represents the sum of prevention and appraisal (conformance) costs and failure/rectification (non-conformance) costs. This concept can be applied to determine the optimum sample size at which the total cost is minimised.

\section{Figure 6 The classic quality cost trade off model}

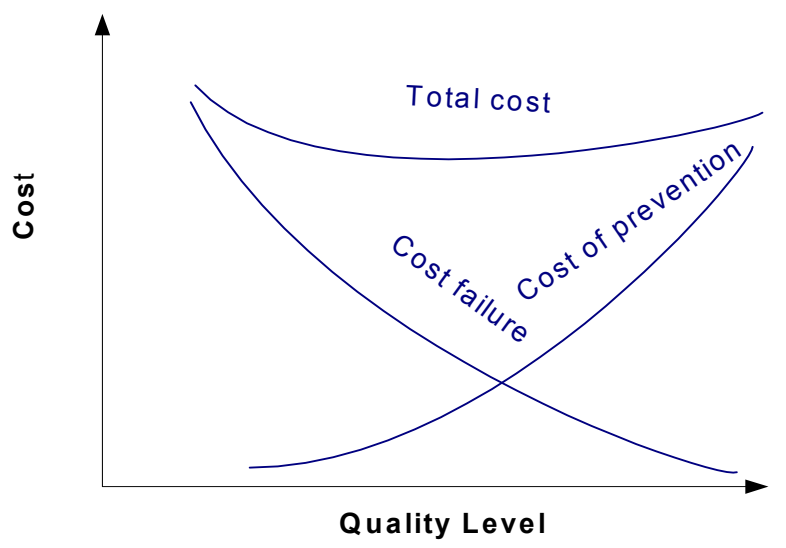


Table 2

Different elements of inspection and rejection costs

\begin{tabular}{|c|c|c|}
\hline Prevention Costs & Appraisal Costs & Failure/rectification costs \\
\hline $\begin{array}{l}\text { Quality system } \\
\text { development } \\
\text { Quality system } \\
\text { management } \\
\text { Assessment of } \\
\text { suppliers and } \\
\text { subcontractors } \\
\text { and maintenance } \\
\text { of master lists } \\
\text { Quality } \\
\text { consultant's fee } \\
\text { Fees of certifying } \\
\text { agent } \\
\text { Audit planning } \\
\text { Quality circles } \\
\text { and other system } \\
\text { improvement } \\
\text { initiative } \\
\text { Development } \\
\text { and } \\
\text { management of } \\
\text { job description } \\
\text { Personnel } \\
\text { selection } \\
\text { All training and } \\
\text { professional } \\
\text { development } \\
\text { Preparation of } \\
\text { project quality } \\
\text { plans including } \\
\text { inspection and } \\
\text { test plans } \\
\text { All costs } \\
\text { associated with } \\
\text { fulfilling the } \\
\text { requirements of } \\
\text { procedure which } \\
\text { are extra-over } \\
\text { those carried out } \\
\text { before the quality } \\
\text { system was in } \\
\text { place. }\end{array}$ & 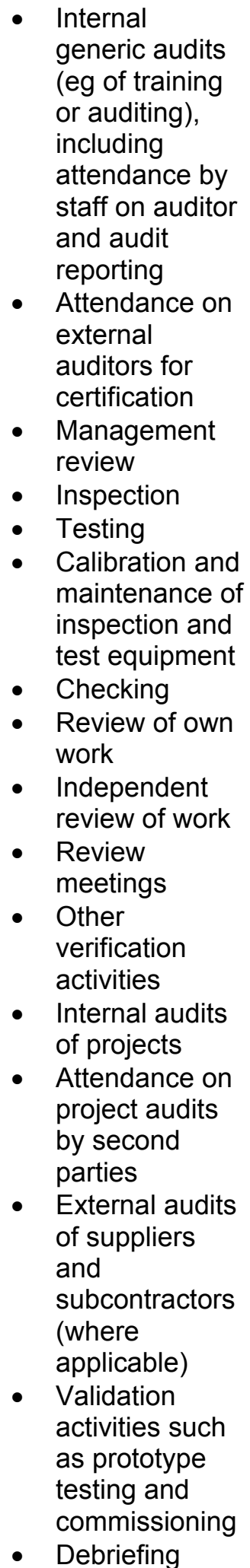 & 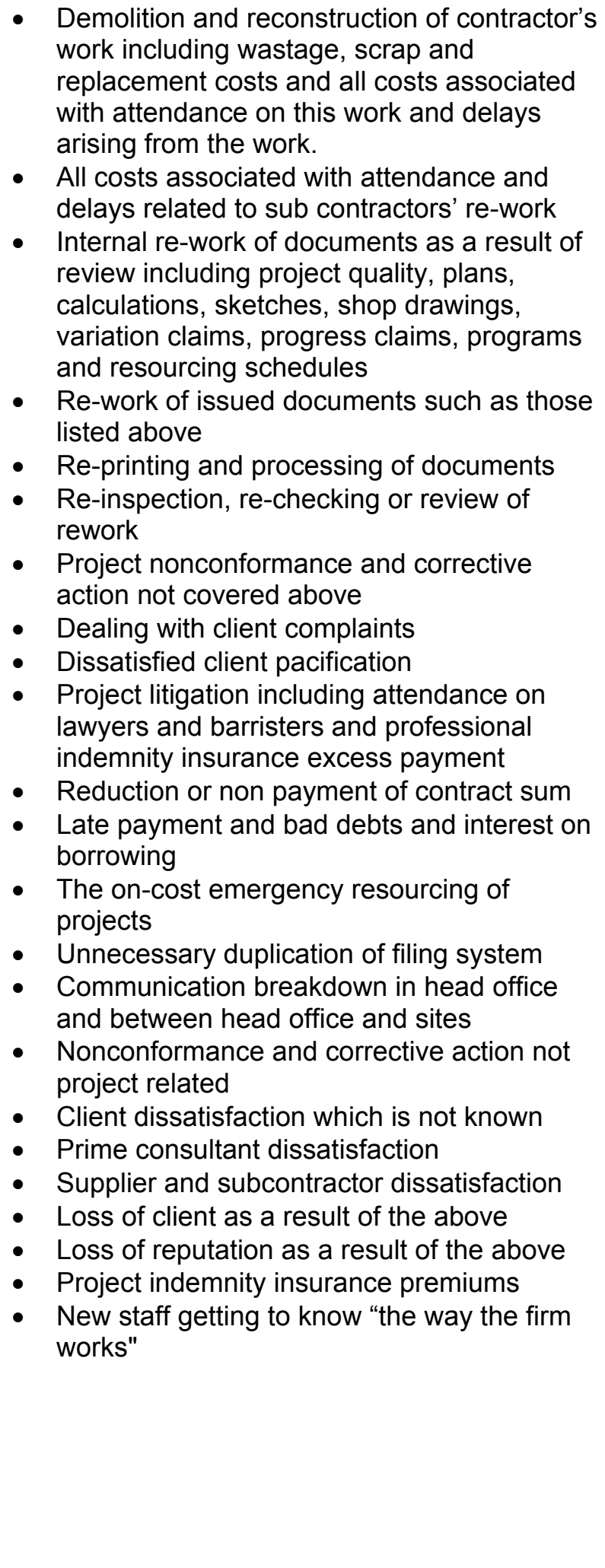 \\
\hline
\end{tabular}


Cost of inspection and rejection

Costs related to construction errors are generally divided into three categories:

$\begin{array}{ll}\text { - } & \text { Prevention } \\ \text { - } & \text { Failure/Rectification }\end{array}$

Prevention costs are all those costs associated with minimising or preventing failure from occurring.

Appraisal costs are those costs associated with quality control and system review of a project.

Failure /rectification costs are costs associated with the service (or product) not meeting client requirements. Despite the fact that failure/rectification costs are the most substantial costs of all, they are often overlooked. Components of these cost items are presented in Table 2

\section{Development of the Model}

In the minimum cost method (MCM) model the sum of prevention and appraisal (conformance) costs and failure/rectification (non-conformance) costs are minimised at a certain quality level. This quality level has a minimum sample size. Using the minimum cost model we can determine the optimum fraction of a lot size for a specified ratio of cost of failure to cost of prevention and appraisal.

Let,

$\mathrm{C}_{\mathrm{t}}=$ the cost of prevention and appraisal

(for detail refer table 2)

$\mathrm{C}_{\mathrm{f}}=$ the cost of failure/rectification (for

detail refer table 2)

$\mathrm{N}=$ lot size

$\mathrm{n}=$ sample size

$r=$ non-conforming items in a sample size,

$\mathrm{n}$

$p=$ average proportion defective (error rate)

Inspection/testing cost $=\mathrm{Ct}_{\mathrm{t}}{ }^{*} \mathrm{n}$

Failure cost $=(r / n){ }^{*} N^{*} C_{f}$

Therefore,

Total cost, $\mathrm{C}=\mathrm{C}_{\mathrm{t}}{ }^{*} \mathrm{n}+(\mathrm{r} / \mathrm{n}){ }^{*} \mathrm{~N}{ }^{*} \mathrm{C}_{\mathrm{f}}$
For minimum $\mathrm{n},(\mathrm{dC} / \mathrm{dn})=0$, After solving equation (15)

$n^{2}=\left(r^{*} N^{*} C f\right) / C t$

$n=(r / n) * N *\left(C_{f} / C_{t}\right)$

replacing $r / n=p$, equation (17) becomes

$\mathrm{n} / \mathrm{N}=\mathrm{p}^{*}\left(\mathrm{C}_{f} / \mathrm{C}_{\mathrm{t}}\right)$

By using equation (18) the sample size can be determined for a particular lot size if the cost ratio is known for the construction process. An example of how to determine the optimal lot size is discussed below.

\section{Example}

In this example the number of defective items ( $r$ ) for a sample has been generated by using a Random Number Generator. An average value of proportion defective $(p)$ can be obtained from a set of $p$ values, which are obtained from the random values of $r$ using Poisson's distribution. In this particular example, assuming values of average proportion defective $(p)$ equal to 0.1 and maximum allowable proportion defective (Q) equal to 0.194 (based on 95\% confidence interval) and for an arbitrary series of $\left(C_{f} / C_{t}\right)$ values $(0,0.5,1.0,1.5$, etc. $)$, $\mathrm{n} / \mathrm{N}$ can be calculated using equation (18). These $n / N$ and $C_{f} / C_{t}$ values are plotted in figure 7 . This figure illustrates an envelope, which is obtained for average $p$ and $Q$ values.

For example, for a cost ratio of 3.0 at lower confidence level, $\mathrm{n} / \mathrm{N}$ is 0.36 and at upper confidence level, $n / N$ is 0.57 . This implies that the number of samples to be inspected or tested per lot depends on the average fraction defective $(p)$ and the ratio of cost of failure $\left(\mathrm{C}_{\mathrm{f}}\right)$ to cost of prevention and appraisal $\left(C_{t}\right)$. In this example, if $n=30$, then the upper limit of the $\mathrm{N}$ value for a cost ratio of 3.0 is 83 . If the cost ratio is lower the percentage of inspection will be lower. For higher failure cost $100 \%$ inspection will be required to satisfy the confidence of owner and contractor. 
Figure $7 \quad$ Fraction of sample size versus ratio of cost of failure to initial cost

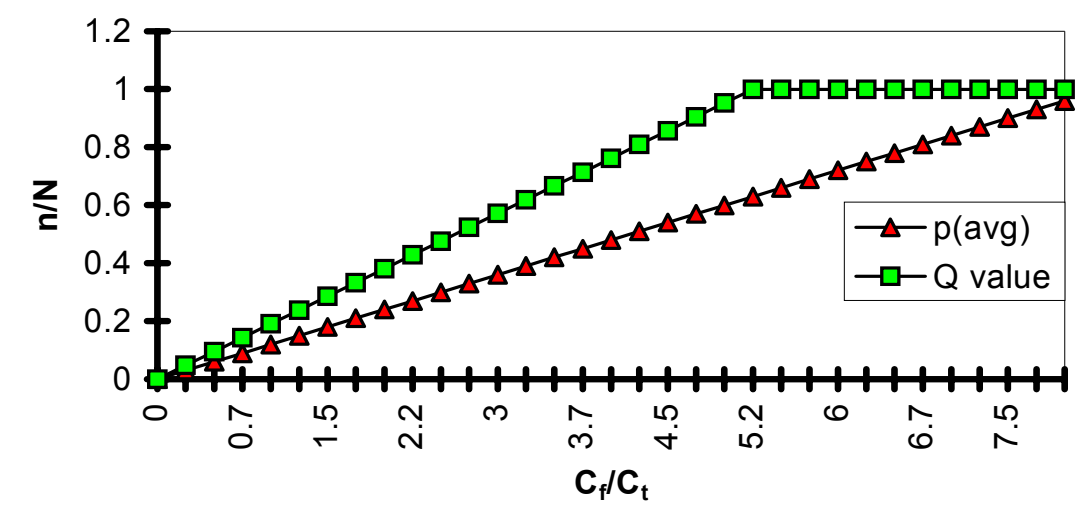

Construction industry related example

The minimum cost method can be used for the calculation of optimum inspection rate for the repetitive tasks in construction. Due to mechanisation and use of same design in construction projects, construction processes are becoming repetitive. Data collected from the Sydney harbour tunnel construction project, shows that a number of tasks were subdivided into lots in a manner that they became repetitive. For example, in the north shore driven tunnel, 2400 meter long ceiling works were divided into 264 reinforced concrete slabs (each slab is approximately $12 \mathrm{~m}$ long $7.6 \mathrm{~m}$ wide). Cost data on this slab construction was collected, including the cost of rework and the cost of inspection/testing. The average ratio of the cost of rework and the cost of inspection/testing was found to be approximately $5.0(\$ 5000 / \$ 1000)$. The proportion defective (error rate) for this sort of work (eg. reinforced concrete construction) can be found from previous studies and historical data, is 0.118 (Stewart 1992). Therefore, using equation (18), the number of slabs to be inspected for the tunnel job (for $p=0.118$ and $N=264$ ) worked out to be 156. According to the records available all slabs were inspected and tested for this job. Therefore, if this method was used, a substantial amount of money could have been saved on inspection and testing without affecting the final quality of the product.

\section{Discussion and Conclusion}

A number of sampling plans are available for the calculation of number of tests/inspections to be performed for a construction task. All the plans are not suitable for the construction industry. In this paper the double sampling plan and the attribute proportional sampling plan are presented with illustrated examples. There are, however, some limitations of these acceptance-sampling methods. These sampling plans do not provide the optimum number of tests at which the cost of tests will be minimised.

An alternative method for the calculation of optimal sample size has been developed. This method is based on minimising total costs including prevention costs, appraisal costs and failure/rectification costs. An example has been presented to illustrate the application of the method. The example has shown that the number of samples to be inspected or tested per lot is not only depended on the average fraction defective but also on the cost of failure and the cost of prevention and appraisal.

The example presented on the construction of repetitive slabs for the Sydney Harbour Tunnel construction project, suggests that a saving can be made using the Minimum Cost Method by determining optimum inspection rate. In this project a number of activities were subdivided into lots. In large 
construction projects this is the norm for effective handling and controlling of construction activities in terms of cost and quality. The construction processes are also becoming more repetitive in residential construction due to the use of the same design and the same construction methods in a number of projects. In the Australian residential construction industry residential builders are involved in construction of project homes. These project homes are of a 'standard' design with inflexible contractual arrangements which make design changes costly and/or impractical. Anecdotal evidence suggests that medium to large residential builders in Australia need to complete in the range of 100 to 200 houses of (relatively) same design scale per annum to provide sufficient return to the business. Therefore, the application of the Minimum Cost Method can be useful for the determination of optimum inspection rate for a number repetitive trade works (eg. foundation work, brickwork, framing, painting, etc.) involved to build these project homes.

The average error rate (proportion defective) for a repetitive construction task is not constant throughout the project. It varies from organisation to organisation and project to project depending on a number of factors. These factors include, site management, experience and skill of the workers and inspectors, site conditions, environment and task complexity (Saha et al., 1999 and Saha, 1998). In future research, modelling of these factors by applying appropriate tools, (eg. fault tree analysis, event tree analysis, and learning curve model), will further enhance the effects of error rate, which may be utilised in predicting realistic inspection rate in construction.

\section{References}

A. A. Auff. Preliminary acceptance criteria for some road dimensions. Proceedings of Applications of Statistics \& Probability in Soil and Structural Engineering, Third International Conference, Sydney, Australia, pp. 352-363, 1975.
A.W. Manton-Hall and R. Sym. Operating characteristics of overlapping and nonoverlapping "means of $n$ " compliance criteria - A detail comparison. Proceedings of Applications of Statistics \& Probability in Soil and Structural Engineering, Second International Conference, Aachen, Germany, pp. 278-291, 1975.

B. Dale. Counting up the Cost, Journal of Total Quality Management, Oct 1991, pp 22-34, 1991.

B.S. Dhillon. Quality control, reliability and engineering design. Marcel and Decker Inc., New York, 1985.

C.D. Ittner. The economics and measurement of quality costs: An empirical investigation, PhD thesis, Graduate School of Business Administration, Harvard University, USA, 1992.

CIDA, Measuring Up or Muddling Through: Best Practice in the Australian Non-Residential Construction Industry, Construction Industry Development Agency, Australia, Master Builders Association, Sydney Australia, pp 59-63. 1995.

DIST. Building for growth: A draft strategy for the building and construction industry, Department of Industry, Science and Tourism, Commonwealth of Australia Publication, February, Canberra, Australia, 1998.

N. Doganaksoy and G.J. Hahn. Moving from every lot inspection to audit sampling. Journal of Quality Technology, Vol. 26, No.4, pp261-273.

E. L. Grant and R. S. Leavenworth. Statistical Quality Control, McGraw-Hill, New York, 1988.

H. Gitlow, A. Oppenheim and R. Oppenheim. Tools and methods for the improvement of quality. Irwin, USA, 1989.

H.Y. Fang. Sampling plan and construction control. Proceedings of Applications of Statistics \& Probability in Soil and Structural Engineering, Second International 
Conference, Aachen, Germany, pp. 323337, 1975.

I. Blyth, QA sharing the experience, The Building Economist, March 1995, pp9-12.

L. Chang and M. Hsie. Developing acceptance sampling methods for quality construction. Journal of Construction Engineering and management, Vol. 121, No. 2, pp. 246-253, 1995.

P.E.D. Love, and H. Li, Quantifying the causes and costs of rework in construction, Journal of Construction Management and Economics, UK, .vol. 18, pp 479-490 2000

R.D. Leitch. Basic reliability engineering analysis. Butterworths \& Co. Ltd., London, 1988.

S.K. Saha, Mathematical Modelling of Construction Error and Optimal Inspection Policy, The Sixth East Pacific Conference on Structural Engineering and

Construction, January 14-16, 1998, The National University of Taiwan, Taipei, pp. 1155-1160, 1998.

M.G. Stewart, The Occurrence and Detection of Errors in Reinforced Concrete Beam Construction. The Department of Civil Engineering and Surveying, research report no. 063.05.1992. The University of Newcastle, NSW,1992.

S. K Saha., , C. Greville, T. Mullins, Simulation Experiment: The effects of experience and interruption in predicting error rate for a construction inspection task. International Congress on Modelling and Simulation Proceedings, The University of Waikato, New Zealand, December 6-9, pp. $1003-1008,1999$

W.W. Hines and D. C. Montgomery. Probability and statistics in engineering and management science. John Wiley \& Sons, Singapore, 1990. 